\title{
Diálogos da Psicologia com Michel Foucault ${ }^{\star}$
}

\author{
Carlysson Alexandre Rangel Gomes ${ }^{\text {Orcid } \star \star}$ Aline Kelly da Silva ${ }^{\text {Orcid }}$ \\ Larissa de Moura Cavalcante Simone Maria Hüning $^{\text {Orcid }}$ \\ Universidade Federal de Alagoas, Maceió, AL, Brasil
}

\begin{abstract}
Resumo
Oobjetivo desse artigo é discutir como a Psicologia no Brasil tem dialogado com as teorizações do filósofo Michel Foucault. Apresentamos os resultados de uma pesquisa que analisou artigos científicos da Psicologia que utilizam as ferramentas teórico-metodológicas do autor. Estes artigos foram publicados em periódicos eletrônicos indexados e estão disponíveis no sítio eletrônico da Biblioteca Virtual em Saúde (BVS-Psi). Os resultados apontam para uma utilização crescente do autor a partir do início dos anos 2000, principalmente na Psicologia Social. Os principais pontos de articulação com o pensamento foucaultiano foram: a problematização da própria produção científica, questionando a sua neutralidade e afirmando, portanto, sua dimensão política; a análise da inter-relação entre a produção de discursos e modos de subjetivação, por sua vez ligada a práticas de governamentalidade, estratégias biopoliticas e normalização da vida; e, por fim, o questionamento das práticas psicológicas como dispositivos éticos de subjetivação.
\end{abstract}

Palavras-chave: Foucault; Psicologia; Psicologia Social.

\section{Dialogues of Psychology with Michel Foucault}

\begin{abstract}
The purpose of this article is to discuss how psychology in Brazil has dialogued with philosopher Michel Foucault's theorizations. We present the results of an investigation that analyzed scientific articles of psychology that use the theoretical and methodological tools of the author. These articles were published in indexed electronic journals and are available on the website of the Virtual Health Library (Biblioteca Virtual em Saude, BVS-Psi). The results point to an increasing use of the author since the early 2000s, especially in social psychology. The main points of articulation with the Foucauldian thought were: the problematization of the scientific production itself, questioning its neutrality and affirming, therefore, its political dimension; the analysis of the interrelationship between the production of discourses and modes of subjectivity connected to governmentality practices, biopolitics strategies, and normalization of life; and, finally, the questioning of psychological practices as ethical devices of subjectification.
\end{abstract}

Keywords: Foucault; Psychology; Social Psychology.

\section{Introdução}

O legado do filósofo Michel Foucault tem sido utilizado cada vez de forma mais frequente em trabalhos da Psicologia, especialmente da Psicologia Social no Brasil, trazendo contribuições e mudanças para este campo do conhecimento, já bastante diverso. Especificamente em relação à Psicologia Social, onde se concentra grande parte dessas produções que dialogam com o pensamento foucaultiano, as referências às perspectivas clássicas dão conta de três grandes tendências: a Psicologia Social Norte-Americana, a Psicologia Social Europeia e a Psicologia Social Latino-Americana (FARR, 2002; FERREIRA, M., 2010). Porém, muitas pesquisas recentes no campo da Psicologia Social situam sua produção a partir de um referencial de estudo foucaultiano e, a partir desse, não apenas rompem com as perspectivas tradicionais, mas introduzem conceitos e operadores teóricos oriundos do pensamento desse autor na produção do conhecimento nessa disciplina.

Assim, a despeito da tensa relação do autor com a Psicologia - cujas críticas podem ser encontradas em trabalhos como Doença Mental e Psicologia (FOUCAULT, 1975), “A Psicologia de 1850 a 1950" (FOUCAULT, 2006a), ou em trabalhos que se referem de modo mais amplo ao que se convencionou chamar "campo psi" (incluindo aí não apenas a Psicologia, mas outros campos

\footnotetext{
^Fonte de financiamento: Conselho Nacional de Desenvolvimento Científico e Tecnológico (CNPq).

$\star \star$ Endereço para correspondência: Av. Lourival de Melo Mota - Tabuleiro do Martins - Maceió-AL. CEP: 57072-970.E-mails: carlysson_al@hotmail.com, kelly_legiao@hotmail.com, simone.huning@ip.ufal.br
}

de saber que se ocupam do eu e da subjetividade, como a psiquiatria e a psicanálise), como no curso Os anormais (FOUCAULT, 2001) e no livro A história da sexualidade (FOUCAULT, 2012) - muitos pesquisadores contemporâneos têm encontrado no pensamento do autor ferramentas potentes para problematizar o presente e afirmar novas formas de se produzir conhecimento em Psicologia.

Nosso interesse de pesquisa surge, desse modo, a partir do contato com esses trabalhos, buscando analisar as aproximações conceituais entre o pensamento desse autor e o campo da Psicologia, discutir quais são as principais ferramentas foucaultianas das quais a Psicologia tem se apropriado, bem como as potencialidades dessa articulação. A partir de trabalhos da Psicologia que dialogam com o pensamento foucaultiano e considerando a proposta do autor de uma análise da relação mútua entre objetivação e subjetivação (FOUCAULT, 2006b), buscamos conhecer e problematizar como essa articulação tem sido construída no campo acadêmico da Psicologia brasileira. Tomamos como alvo neste artigo a discussão sobre as principais contribuições do autor para o campo da Psicologia, concentrada, como mostraremos a seguir, principalmente na Psicologia Social.

\section{Método}

Realizamos um levantamento bibliográfico através da ferramenta de busca da Biblioteca Virtual em Saúde - Psicologia Brasil (BVS-Psi Brasil), pelo acesso a Bases em Texto Completo. Esse recurso permite que a pesquisa acesse 
artigos completos publicados em diferentes bases de dados, periódicos e bibliotecas eletrônicas. A busca e a inclusão dos artigos no material analisado aconteceram pela ocorrência conjunta dos descritores "Psicologia" e "Foucault".

Não se fez delimitação temporal em relação ao período inicial das publicações, na medida em que nos interessou analisar o desenvolvimento dessas produções também a partir de uma perspectiva histórica. Assim, inicialmente foram considerados todos os materiais que correspondessem aos critérios de busca, disponíveis online. Estabelecemos como limite temporal final os materiais publicados até 2013, considerando sua disponibilidade nas revistas eletrônicas.

Após a identificação inicial do material pela correspondência aos descritores utilizados na busca, os resumos foram lidos para análise dos aspectos relativos aos objetivos específicos desta pesquisa. Tomamos como principal critério de inclusão dos artigos o fato de eles dialogarem com as teorizações de Michel Foucault no campo da Psicologia.

Nos casos em que o resumo não permitiu a decisão a partir dos critérios adotados, realizou-se a leitura na íntegra do material para que pudéssemos decidir se iríamos incluir o material ou não. Após o levantamento do material, procuramos identificar quais os conceitos foucaultianos utilizados nos materiais analisados e como esses conceitos se articulam com a Psicologia.

Ao total, foram identificados 58 artigos publicados em periódicos eletrônicos a partir da ferramenta de busca Biblioteca Virtual em Saúde - Psicologia Brasil (BVS-Psi Brasil). Desses 58 artigos, 9 foram excluídos durante a pesquisa, pois, mesmo tendo apresentado os descritores para a análise, não articulavam as teorizações de Michel Foucault com a Psicologia, e esse foi um dos critérios para a seleção do material. Da totalidade de artigos analisados, 28 relacionavam-se ao campo da Psicologia Social.

\section{Resultados e discussão}

A obra de Michel Foucault possui uma potência crítica não só para a Psicologia, mas para as Ciências Humanas em geral. $\mathrm{O}$ autor considerava que seus estudos pudessem ser usados como uma caixa de ferramentas, e não como teorias universais (FOUCAULT, 1979). E é a partir dessa caixa de ferramentas que a Psicologia vem recentemente repensando suas práticas como ciência, conforme o levantamento do material analisado aponta.

Como não delimitamos nenhum recorte temporal em relação ao início das publicações a serem analisadas, constatamos que a utilização das teorizações de Michel Foucault no campo da Psicologia é um fenômeno relativamente recente, já que os primeiros trabalhos publicados em periódicos científicos indexados nas bases de busca são do ano de 2001, sendo eles um artigo de Bastos (2001) e um artigo de Coimbra e Nascimento (2001).

Fractal, Rev. Psicol., v. 31 - n. 1, p. 20-26, 2019
A partir do levantamento do material, podemos afirmar que ao longo dos anos houve um aumento significativo do número de publicações que são fundamentadas pelo referencial teórico-metodológico foucaultiano. Esse aumento está ilustrado no gráfico a seguir.

Gráfico 1 - Número de artigos por ano

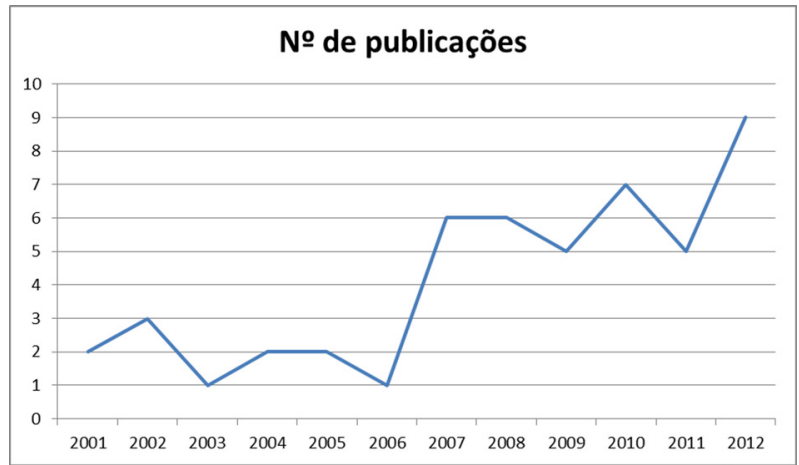

Conforme o gráfico 1 permite visualizar, o número de publicações por ano que utilizam a obra de Michel Foucault como fundamentação teórica na Psicologia cresceu significativamente. Além disso, não somente o número de publicações aumenta no decorrer dos anos, como também há um aumento do uso de diferentes conceitos teóricos desenvolvidos por Foucault no decorrer de sua obra. O aumento dessa quantidade de conceitos, que abordaremos a seguir, pode ser analisado como uma intensificação do aprofundamento teórico das obras foucaultianas por parte dos pesquisadores, e, consequentemente, da potência de crítica que um trabalho que utiliza esse referencial teórico pode trazer.

Devido à complexidade da obra de Michel Foucault, nós optamos, para fins didáticos, por organizar nossa análise a partir da divisão do pensamento do autor em três domínios, tomando por base um critério teórico-metodológico: o arqueológico, o genealógico e o da ética (VEIGA-NETO, 2011). É importante ressaltar, entretanto, que essa divisão não significa que cada domínio possa ser tratado como um momento isolado do autor e nem que a passagem de um a outro domínio ocorra de forma linear e excludente. $\mathrm{Na}$ obra de Foucault, o início de um novo domínio não significa o término do anterior. Pelo contrário, eles vão se incorporando e se agregando. Tendo como referência essa divisão apresentada por Veiga-Neto (2011), discutiremos a inserção dos conceitos do autor no campo da Psicologia, a partir dos trabalhos analisados, considerando que um mesmo artigo pode relacionar-se simultaneamente a mais de um dos domínios apresentados. Assim, embora indiquemos o número de artigos situados em cada um dos três domínios, a soma deles três ultrapassa o número total de artigos analisados.

\section{O domínio da arqueologia}

No domínio da arqueologia, Foucault está interessado em utilizar seu método arqueológico como uma forma de analisar as regras discursivas da formação dos saberes. A partir desse método, o autor passou a compreender a história como algo que não é linear, homogêneo e contínuo. No momento em que o autor trata os documentos históricos como 
monumentos, ele passa a identificar as rupturas e descontinuidades históricas na produção de certas verdades, buscando estabelecer relações, séries e conjuntos discursivos no próprio tecido documental (FOUCAULT, 2008a).

Essa possibilidade de identificar e analisar essas descontinuidades históricas permitiu ao autor questionar a própria ciência como uma verdade neutra e absoluta, pois, para o autor, a construção de todo saber é atravessado por relações de poder, como ele mesmo fala: "Não há relação de poder sem constituição correlata de um campo de saber, nem saber que não suponha e não constitua ao mesmo tempo relações de poder" (FOUCAULT, 1996, p. 29).

Dos artigos analisados, 35 dialogavam com esse domínio foucaultiano. A seguir, discutimos as principais questões e conceitos abordados nesses trabalhos, bem como suas contribuições ao campo da Psicologia.

Nos artigos analisados, a arqueologia foi trazida como uma ferramenta teórico-metodológica que permitia ao pesquisador questionar a suposta neutralidade científica presente no campo da Psicologia e também contestar a produção de verdades provenientes desse campo. Tal posicionamento é expresso, por exemplo, no artigo de Coimbra e Nascimento (2001, p. 247), um dos primeiros encontrados que propõe o diálogo da Psicologia com o autor, afirmando que:

A potência do pensamento de Foucault em nossas práticas diz respeito a desconstrução de todas essas crenças ao apontá-las enquanto produções histórico-sociais, indicando a multiplicidade presente nos diferentes objetos que estão no mundo, negando com isso a possibilidade de apreendê-los de forma objetiva e neutra, colocando em questão nosso conhecimento baseado em verdades.

A contestação da neutralidade científica ocorre, nos trabalhos que dialogam com a arqueologia, situando o caráter histórico-social da produção do saber psicológico. Atentando para esse aspecto, Prado Filho (2011, p. 465), em artigo publicado 10 anos após a primeira publicação identificada pelos nossos critérios de busca, também situa a contribuição da arqueologia para a produção do conhecimento em Psicologia, argumentando que:

em vez de se perguntar sobre as condições para a existência de verdades num campo discursivo, um estudo arqueológico ocupa-se centralmente da formação histórica e da disciplinarização de um campo de saber - importa mais à análise arqueológica o caráter disciplinar da formação de um campo de saberes e práticas, do que a cientificidade de um domínio de conhecimento.

Ao mesmo tempo em que os estudos arqueológicos de Foucault levam à recusa da ideia de neutralidade da Psicologia e de outras ciências sociais e humanas, também indicam a existência de um sistema regulador de discursos e saberes que permitem a emergência de verdades científicas, situadas historicamente, demonstrando, assim, que essas verdades são provisórias, elas só obedecem a uma episteme que é variante com o passar dos séculos. Sendo assim, as verdades científicas só podem aparecer em um determinado contexto sociocultural e circunscritas a determinadas condições.
Essa análise da produção do conhecimento possibilitada pela arqueologia, muitas vezes referida como desnaturalização de verdades, torna-se bastante produtiva para a Psicologia ao desestabilizar alguns de seus conceitos e teorias. No material analisado, o conceito de subjetividade/subjetivação é um dos que, sob a perspectiva arqueológica, foi bastante discutido pelos pesquisadores. $\mathrm{O}$ conceito de subjetividade é algo muito caro à Psicologia, ao mesmo tempo em que controverso, e, portanto, merece atenção. A partir das teorizações foucaultianas, a subjetividade passou a ser repensada como algo que é histórico, local e fruto de relações de saber e poder (PRADO FILHO; MARTINS, 2007). Os diálogos da Psicologia com o pensamento foucaultiano não impõem um novo conceito de subjetividade, substituindo e invalidando outras definições; porém introduzem uma nova compreensão dos processos de subjetivação que passará a coexistir com outras formas de saber já tradicionais nesse campo disciplinar.

O artigo de Soler (2008, p. 572) ilustra essa nova compreensão, ao afirmar que a arqueologia permite "uma crítica com relação a certas tradições psicológicas que entendem a subjetividade através de uma concepção anistórica e universalizada". Do mesmo modo, Silva e Méllo (2011) referem-se à importância do uso da arqueologia na ciência psicológica, levando ao abandono da concepção de subjetividade como uma entidade dada e imutável, regida por leis psíquicas universais: "Deve-se passar a concebê-la como processualidade que se realiza num plano histórico-político, no qual o sujeito emerge como efeito de relações de poder" (SILVA; MÉLLO, 2011, p. 368).

A análise dos modos de subjetivação e das subjetividades estará ligada, a partir do trabalho de Foucault, ao estudo dos discursos e suas regras de formação, também compreendidos a partir do domínio da arqueologia. Passa-se a entender o discurso como algo que é sempre produzido por um embate de forças imersas em relações de saber e poder e que inscreve sua marca nos corpos, produzindo uma maneira de pensar e agir de acordo com esses discursos (FOUCAULT, 2005). Nas publicações da Psicologia analisadas, encontramos ainda o uso do conceito foucaultiano de discurso vinculado à produção de subjetividades. Lembramos que, para o autor, o discurso não tem função de descrever ou representar um objeto; ao invés disso, o discurso é quem produz o objeto, ou seja, nós também somos constituídos pelos discursos. A relação entre a produção de discursos e subjetivações pode ser assim definida:

Subjetivações se edificam em discursos, em relações de enunciados, mas não se restringem a eles. É necessário compreender que regulamentos de condutas são engendrados nesses discursos; que práticas e técnicas, autoridades, lugares, posições e aparatos constituem regimes de subjetivação e gerência de práticas (MÉLLO; PAOLO, 2007, p. 494).

Temos, portanto, uma articulação da Psicologia com o domínio da arqueologia que envolve o questionamento do conhecimento científico, discursos e modos de subjetivação. Essa articulação tangencia o conceito de sujeito, que deixa de ser entendido a partir de uma suposta essên- 
cia universal ou de estruturas psíquicas, para ser pensado como um emaranhado de relações de força e de poder que o atravessam e constituem. A subjetividade passa, dessa maneira, a ser entendida como fruto de relações que se produzem localmente e são fluidas. Uma das principais contribuições de Michel Foucault, ao colocar em discussão a subjetividade como fruto de processos pelos quais nos constituímos como sujeitos, é possibilitar recusas ao que somos e abrir possibilidades de construção de outros processos de subjetivação.

\section{O domínio da genealogia}

Conforme já descrito, a passagem de um domínio a outro da obra foucaultiana não implica dizer que o domínio anterior foi abandonado. No que se refere à genealogia, por exemplo, Castro (2009, p. 185) argumenta que

[...] não devemos entender a genealogia de Foucault como uma ruptura e, menos ainda, como uma oposição à arqueologia. Arqueologia e genealogia se apoiam sobre um pressuposto comum: escrever a história sem referir a análise à instância fundadora do sujeito.

Durante o período genealógico, Foucault toma como principal objeto de estudo a análise das formas de exercício do poder e, diferentemente de outros autores, entende o poder como algo positivo, como algo que produz comportamentos, sujeitos e embates de forças. A partir de suas obras, Foucault vai mostrando como o sujeito moderno é fruto de relações de saber e poder, pois a genealogia se torna uma forma para "entendimento acerca dos processos pelos quais os indivíduos se tornam sujeitos como resultado de um intricado processo de subjetivação que se dá no interior de redes de poderes, que os capturam, dividem, classificam" (VEIGA-NETO, 2011, p. 55).

Rompendo com a ideia de um sujeito universal e racional, Foucault (1979, p. 22) afirma que nossos corpos são historicizados, que nossas subjetividades podem ser datadas, que a genealogia nos permite "mostrar o corpo inteiramente marcado de história e a história arruinando o corpo." Conforme um dos artigos analisados aponta, "sua inovação consiste em assinalar que os objetos, saberes e sujeitos que estão no mundo não tem uma existência 'em si', não são naturais, mas forjados historicamente por práticas datadas que os objetivam, como um trabalho jamais completado" (COIMBRA; NASCIMENTO, 2001, p. 246).

Essa nova concepção de sujeito, formulada a partir de Foucault pela Psicologia, traz uma série de questionamentos para o campo. Um dos trabalhos analisados ilustra bem como o uso da genealogia ofereceu ferramentas para a produção desses questionamentos, pois, segundo Escóssia e Mangueira (2005, p. 94), o uso das problematizações de Michel Foucault na Psicologia permitiu compreender que:

[...] o sujeito não é um dado preexistente e de que sua forma não é definitiva: sua natureza é fundada e re-fundada historicamente [...] a própria Psicologia é produto e faz parte de uma trama de saberes e poderes voltada para a disciplina e controle dos corpos individuais e coletivos [...] o abalo se deve ao fato de a Psicologia ter pautado suas práticas em uma crença substancialista do sujeito. O sujeito psíquico era concebido como entidade acabada, idêntica a si própria, imutável, a-histórico.

Outra contribuição importante que o uso da genealogia proporcionou nos trabalhos analisados foi a compreensão de que o discurso científico é também um discurso político. Na obra de Foucault, a ciência passa a ser compreendida como fruto de relações de saber e poder; portanto, não pode ser considerada neutra e distante dos embates políticos presentes no corpo social de diferentes períodos históricos. Nesse sentido, podemos assinalar um encontro da arqueologia com a genealogia.

Alguns trabalhos analisados colocam em discussão a neutralidade científica. De acordo com Silveira e Furlan (2003, p. 175), por exemplo, o pensamento foucaultiano nos permite superar "a neutralidade difusamente presente em diversos grupos intelectuais, de que 'fazer ciência não é fazer política', ou a concepção na qual a ciência está dissociada de qualquer disputa pelo poder".

Essa ideia de que fazer ciência é fazer política se mostra de suma importância para o campo da Psicologia, pois permite questionar diversas práticas psicológicas que possuem um intuito de normalização da vida, e não de compreender a vida como uma potência criativa. As verdades produzidas a partir do campo científico passam a ser vistas como provisórias e históricas; verdades que são oriundas de relações de saber e poder; verdades que podem, dessa maneira, ser contestadas de diversas formas.

É no domínio genealógico que Foucault (1996) publica Vigiar e Punir, onde traça uma genealogia da penalidade moderna. Nesse momento, o autor constrói uma série de conceitos que permitem problematizar o funcionamento da prisão no Ocidente. Esses conceitos também ajudam a questionar uma série de práticas psicológicas principalmente no campo jurídico.

Nesse momento, Foucault foca seus estudos no chamado poder disciplinar, um poder que tenta regular e normatizar os corpos através de sanções e da vigilância. E é a partir daí que ele vai desenvolver uma análise do exame. Segundo ele:

$\mathrm{O}$ exame combina as técnicas da hierarquia que vigia e as técnicas da sanção que normaliza. É um olhar normalizador, uma vigilância constante, que permite qualificar, classificar, castigar. Estabelece sobre os indivíduos uma visibilidade mediante a qual se lhes diferencia e sanciona (FOUCAULT, 1996, p. 186-187).

Essa análise do exame permite questionar diversas práticas psicológicas dentro do âmbito jurídico, pois muitas dessas práticas são baseadas em normas sociais; normas que muitas vezes servem para regular a conduta e os comportamentos dos indivíduos, tentando encaixá-los em um modelo dito normal. Um dos artigos analisados discute que, a partir do pensamento foucaultiano, é possível problematizar que a "justiça não é neutra, mas é produtora de um padrão normalizador e regulador do comportamento" (SCISLESKI; GUARESCHI, 2011, p. 223). As autoras também afirmam que:

As tecnologias de vigilância, sempre apoiadas em algum saber, são produtoras de discursos que conduzem o caminho 
que levará ao encontro com a verdade. O pensamento foucaultiano, entretanto, propõe um caminho oposto ao dessa busca, mostrando como a verdade é produzida através de relações de poder e de tecnologias de saber - ou seja, muito distante de ser uma essência a ser descoberta ou revelada, por exemplo (SCISLESKI; GUARESCHI, 2011, p. 221).

Em seus últimos trabalhos no domínio da genealogia, Foucault passa a se interessar pelo que ele chama de "governamentalidade", que pode ser entendida como:

[...] o conjunto constituído pelas instituições, os procedimentos, análises e reflexões, os cálculos e as táticas que permitem exercer essa forma bem específica, embora muito complexa, de poder que tem por alvo principal a população, por principal forma de saber a economia política e por instrumento técnico essencial os dispositivos de segurança (FOUCAULT, 2008b, p. 143).

A governamentalidade tem como foco principal o governo das populações. É uma arte de governar que tem a razão de Estado como princípio de inteligibilidade, sempre preocupada em como governar na medida: não governar demais, a ponto de se tornar uma ditadura, e nem governar de menos (FOUCAULT, 2008c). Essa noção de governamentalidade também se faz presente nas publicações que colocam em diálogo o trabalho de Foucault com a Psicologia.

Essa forma de exercício do poder analisada por Foucault desemboca em dois conceitos-chave por ele desenvolvidos, a biopolítica e o biopoder. Dentre as estratégias biopolíticas podemos situar "[as] políticas públicas sobre o corpo social [o indivíduo e sua vida nua], que são supostamente justificadas pela análise das necessidades e atitudes humanas, por um lado, e as medidas razoáveis e prima facie corretas para enfrentá-las, por outro lado" (SCHARAMM, 2006 apud VENTURA, 2010, p. 29). Já o biopoder pode ser entendido como uma forma de exercício da biopolítica, pois, como Foucault (2005, p. 297) explica, o biopoder funciona como:

[...] uma tecnologia que, por sua vez, é centrada não no corpo, mas na vida; uma tecnologia que agrupa os efeitos de massas próprios de uma população, que procura controlar a série de eventos fortuitos que podem ocorrer numa massa viva; uma tecnologia que procura controlar (eventualmente modificar) a probabilidade desses eventos, em todo caso, compensar seus efeitos. É uma tecnologia que visa, portanto não o treinamento individual, mas, pelo equilíbrio global, algo como uma homeóstase: a segurança do conjunto em relação aos seus perigos internos.

Essa relação entre governamentalidade, biopolítica e biopoder se mostra bastante produtiva em articulação com a Psicologia. A partir dos artigos analisados, constatamos que esse conjunto teórico está principalmente vinculado a problematizações que envolvem produção de subjetividade e normalização da vida. Conforme Minayo-Gomez e Barros (2002, p. 660) apontam:

A arte de governar/gerir/regulamentar a vida é seu objetivo mais importante, pois define os modos de subjetivação adequados e submete os inadequados à disciplinarização e à regulamentação. A lógica dessa arte de governar é, princi- palmente, a tutela e a normalização.

O trabalho de Soler (2008, p. 576) também indica como, a partir de uma análise biopolítica das relações de poder, pode-se afirmar que existe uma

[...] normalização como via de regra aos fatores que envolvem os cuidados e as políticas de higienização, de alimentação, e o controle das taxas de natalidade e de mortalidade. Aqui a subjetividade aparece como uma produção regulada na caracterização de parâmetros que intensificam a vida.

\section{O domínio da ética}

No domínio da ética, Foucault desenvolve uma análise do sujeito ético moderno. Para o autor, é importante fazer uma separação entre a moral e a ética. Em Foucault, a moral seria um conjunto de regras prescritas por diferentes instituições, como a família, a escola, a igreja, o trabalho; já a ética diz respeito às relações que o sujeito estabelece consigo mesmo em face dessas regras presentes no corpo social. Segundo Castro (2009, p. 156), “o termo ético refere-se a todo esse domínio da constituição de si mesmo como sujeito moral".

É nesse complexo emaranhado de assujeitamentos e resistências a essas regras morais que Foucault enxerga a possibilidade da construção de uma arte de viver, intimamente ligada à ampliação do grau de liberdade com que se pode viver e a uma produção de estratégias para que se possa estabelecer uma alternância de posicionamento nos jogos de poder e verdade (NARDI; SILVA, 2005).

Em um dos artigos analisados, o conceito de ética também é associado às chamadas "técnicas de si". Os autores utilizam esse conceito para problematizar a produção de subjetividade, pois, conforme eles argumentam, "As técnicas de si seriam, então, procedimentos ou mecanismos capazes de colocar em funcionamento certas operações do sujeito com relação a ele mesmo. E, se são capazes disso, tornam-se, então, dispositivos ou ordenadores de efeitos. Isso resulta na forma como se experimenta a vida como uma vida 'de si'”' (SILVA; MÉLLO, 2011, p. 377).

A partir dessa noção de ética, pode-se concluir que o sujeito ético moderno se constitui mediante práticas que são historicamente construídas em cada cultura (NARDI; SILVA, 2005). Nos artigos analisados constatamos que as práticas psicológicas são consideradas um dispositivo ético e, portanto, produtor de subjetividade. Conforme Ferreira Neto e Penna (2006, p. 382) argumentam, "a clínica passa a ser entendida, atualmente, menos como um modo de intervenção e mais como um dispositivo produtor de subjetividade - em suma, como um dispositivo ético de subjetivação".

\section{Considerações finais}

O material analisado nos indica que as publicações da Psicologia que dialogam com as teorizações e a obra de Michel Foucault, em periódicos científicos indexados nas bases consultadas, iniciaram a partir do ano de 2001; portanto, são publicações recentes, que apresentam um crescimento gradativo no decorrer dos anos. Outro elemento interessante de ser pontuado é que, ao longo dessa produção, mais ferramentas conceituais do autor são trazidas 
para o campo da Psicologia. Nossa pesquisa não contemplou outras formas de publicação, pois entendemos que esses materiais nos permitem acompanhar de forma mais dinâmica aquilo que se tem produzido e legitimado em um campo científico.

A utilização de ferramentas teórico-metodológicas de Michel Foucault pela Psicologia agrega novos elementos ao modo como se produz conhecimento nesse campo de saber. Como vimos, os principais pontos de articulação com o pensamento foucaultiano foram a problematização da própria produção científica, questionando a sua neutralidade e afirmando, portanto, sua dimensão política; a análise da inter-relação entre a produção de discursos e modos de subjetivação, por sua vez ligada a práticas de governamentalidade, estratégias biopolíticas e normalização da vida; e, por fim, o questionamento das práticas psicológicas como dispositivos éticos de subjetivação.

Tais elementos levam à ruptura de uma concepção do que é o conhecimento e o sujeito para a Psicologia. À recusa de um sujeito psicológico universal relaciona-se uma postura epistemológica não mais preocupada com a produção de verdades universais, mas de questionamento do próprio conhecimento científico e seus efeitos de governamentalidade, subjetivação e normalização. Esse aspecto situa a produção de verdades da própria ciência psicológica como intimamente ligada a práticas políticas.

A normalização das subjetividades que a Psicologia vem produzindo também é destacada em muitos dos trabalhos analisados, que denunciam como muitas práticas psicológicas têm como principal função enquadrar um sujeito na esfera do "normal", considerando suas diferenças e individualidades como um desvio a ser corrigido.

É importante salientar que em todos os domínios foucaultianos discutidos a subjetividade é sempre alvo de discussão. Com base nas produções científicas analisadas, pode-se afirmar que a aproximação de Foucault com o campo da Psicologia tem como elo o conceito de sujeito. Entende-se que são justamente as modificações no modo de entender o sujeito - a partir de Foucault não mais o "sujeito psicológico", da interioridade e da essência - e a análise dos processos sociais e culturais de subjetivação, numa perspectiva local, situacional e historicamente datada, que permitem a articulação do pensamento foucaultiano com os saberes psicológicos.

As ferramentas teórico-metodológicas trazidas da obra foucaultiana para a Psicologia são, sobretudo, utilizadas na Psicologia Social, com foco na análise e problematização dos modos de subjetivação e governo das subjetividades, recolocando a questão foucaultiana de pensarmos sobre aquilo que estamos nos tornando. Tal uso passa a configurar uma nova perspectiva em Psicologia Social, que, por suas dimensões epistemológicas, metodológicas, ontológicas e éticas, já não cabe nas definições das perspectivas clássicas mencionadas no início desse texto.

Embora Foucault seja ele mesmo um crítico do enquadramento do saber em campos disciplinares, questionando o modo como se constituem essas fronteiras (FOUCAULT, 2014), consideramos importante a análise de sua influência para a Psicologia (assim delimitada como campo disciplinar), exatamente por compreendermos, em consonância com esse autor, os processos de construção e legitimação do conhecimento como permeados por relações de poder. Ao sinalizarmos os pontos de contato, contribuições e rupturas produzidas na Psicologia, buscamos não produzir mais demarcação de fronteira desse campo de saber, mas exatamente apontar para sua permeabilidade e flexibilidade. Ao constituir-se sempre como prática inacabada, no exercício da crítica sobre o que produz, a Psicologia se atualiza, se contradiz e se transforma, não apenas como decorrência de um desenvolvimento epistemológico, mas sobretudo ético-político.

\section{Referências}

BASTOS, Rogério Lustosa. Psicanálise e o pensamento científico: entre o fisicalismo e/ou a contraciência em diferentes modos de subjetividade. Psicologia USP, São Paulo, v. 12, n. 1, p. 89-119, 2001. Disponível em: https:/www.revistas.usp.br/ psicousp/article/view/108124. Acesso em: 4 nov. 2018.

CASTRO, Edgardo. Vocabulário de Foucault: um percurso pelos seus temas, conceitos e autores. Tradução de Ingrid Müller Xavier. Belo Horizonte: Autêntica, 2009.

COIMBRA, Cecilia Maria Bouças; NASCIMENTO, Maria Livia do. O efeito Foucault: desnaturalizando verdades, superando dicotomias. Psicologia: Teoria e Pesquisa, Brasília, v. 17, n. 3 , p. $245-248,2001$. Cross ${ }^{\text {Ref }}$

ESCÓSSIA, Liliana da; MANGUEIRA, Maurício. Para uma Psicologia clínico-institucional a partir da desnaturalização do sujeito. Revista do Departamento de Psicologia - UFF, Niterói, v. 17, n. 1, p. 93-101, jan./jun. 2005. Cross ${ }^{\text {Ref. }}$

FARR, Robert M. As raizes da Psicologia Social moderna. 5 ed. Petrópolis, RJ: Vozes, 2002.

FERREIRA NETO, João Leite; PENNA, Lícia Mara Dias. Ética, clínica e diretrizes: a formação do psicólogo em tempos de avaliação de cursos. Psicologia em Estudo, Maringá, v. 11, n. 2, p. 381-390, maio/ago. 2006. Disponível em: http://www. scielo.br/pdf/pe/v11n2/v11n2a16. Acesso em: 12 dez. 2016.

FERREIRA, Maria Cristina. A Psicologia Social contemporânea: principais tendências e perspectivas nacionais e internacionais. Psicologia: Teoria e Pesquisa, Brasília, v. 26, n. especial, p. 51-64, 2010. Cross ${ }^{\text {Ref. }}$

FOUCAULT, Michel. Doença mental e Psicologia. Rio de Janeiro: Tempo Brasileiro, 1975.

FOUCAULT, Michel. Microfisica do poder. São Paulo: Graal, 1979.

FOUCAULT, Michel. Vigiar e punir: nascimento da prisão (1975). 38. ed. Petrópolis, RJ: Vozes, 1996.

FOUCAULT, Michel. Os anormais (1974-1975): curso no Collège de France. São Paulo: Martins Fontes, 2001.

FOUCAULT, Michel. Em defesa da sociedade: curso no Collège de France (1975-1976). São Paulo: Martins Fontes, 2005.

FOUCAULT, Michel. A Psicologia de 1850 a 1950. In: MOTTA, Manoel Barros da (Org.). Problematização do Sujeito: Psicologia, Psiquiatria e Psicanálise. 2. ed. Rio de Janeiro: Forense Universitária, 2006a. Coleção Ditos \& Escritos, v. 1, p. 133-151. 
FOUCAULT, Michel. Foucault. In: MOTTA, Manoel Barros da (Org.). Ética, Sexualidade, Política. 2. ed. Rio de Janeiro: Forense Universitária, 2006b. Coleção Ditos \& Escritos, v. 5, p. 234-239.

FOUCAULT, Michel. A arqueologia do saber (1969). Rio de Janeiro: Forense Universitária, 2008a.

FOUCAULT, Michel. Segurança, território, população: curso no Collège de France (1977-1978). São Paulo: Martins Fontes, $2008 b$.

FOUCAULT, Michel. Nascimento da biopolítica: curso no Collège de France (1978-1979). São Paulo: Martins Fontes, 2008c.

FOUCAULT, Michel. História da sexualidade: a vontade de saber (1976). Rio de Janeiro: Graal, 2012. v. 1.

FOUCAULT, Michel. A ordem do discurso (1970). São Paulo: Loyola, 2014.

MÉLLO, Ricardo Pimentel; PAOLO, Angela Flexa Di. Subjetivações, identidades e o linguajar. Estudos e Pesquisas em Psicologia, Rio de Janeiro, v. 7, n. 3, p. 490-501, 2007.

MINAYO-GOMEZ, Carlos; BARROS, Maria Elizabeth Barros de. Saúde, trabalho e processos de subjetivação nas escolas. Psicologia: Reflexão e Crítica, Porto Alegre, v. 15, n. 3, p. 649663, 2002. Cross ${ }^{\text {Ref. }}$

NARDI, Henrique Caetano; SILVA, Rosane Neves da. Ética e subjetivação: as técnicas de si e os jogos de verdade contemporâneos. In: GUARESCHI, Neuza; HÜNING, Simone Maria (Org.). Foucault e a Psicologia. Porto Alegre: Abrapso Sul, 2005. p. 93-105.

PRADO FILHO, Kleber. Para uma arqueologia da Psicologia social. Psicologia \& Sociedade, Florianópolis, v. 23, n. 3, p. 464-468, 2011. Cross ${ }^{\text {Ref }}$

PRADO FILHO, Kleber; MARTINS, Simone. A subjetividade como objeto da(s) Psicologia(s). Psicologia e Sociedade, Porto Alegre, v. 19, n. 3, p. 14-19, 2007. Cross ${ }^{\text {Ref }}$

SCISLESKI, Andrea; GUARESCHI, Neuza. Promete falar a verdade? Psicologia \& Sociedade, Florianópolis, v. 23, n. 2, p. 220-227, 2011. Cross ${ }^{\text {Ref }}$

SILVA, Alyne Alvarez; MÉLLO, Ricardo Pimentel. Subjetivação e governamentalidade: questões para a

Psicologia. Fractal: Revista de Psicologia, Niterói, v. 23, n. 2, p. 367-387, 2011. Cross $^{\text {Ref }}$

SILVEIRA, Fernando de Almeida; FURLAN, Reinaldo. Corpo e alma em Foucault: postulados para uma Metodologia da Psicologia. Revista Psicologia USP, São Paulo, v. 14, n. 3, p. 171-194, 2003. Cross ${ }^{\text {Ref. }}$

SOLER, Rodrigo Diaz de Vivar Y. Uma história política da subjetividade em Michel Foucault. Fractal: Revista de Psicologia, Niterói, v. 20, n. 2, p. 571-582, 2008. Cross ${ }^{\text {Ref }}$

VEIGA-NETO, Alfredo. Foucault e a educação. 3. ed. Belo Horizonte: Autêntica, 2011.

VENTURA, Miriam. A transexualidade no tribunal: saúde e cidadania. Rio de Janeiro: EdUERJ, 2010.

Recebido em: 15 de dezembro de 2015

Aceito em: 22 de novembro de 2018 